\title{
Pensar las alternativas A propósito de las reflexiones de Franz Hinkelammert
}

Nuestra sociedad vive acelerada. Si bien todas las sociedades han tenido problemas con el tiempo, la nuestra parece pretender desbancarlo. Se proyecta cada vez más hacia el futuro con el intento de prosperar y en esta misma medida crece la paradoja de que cada vez hay menos proyectos y más proyecciones. La mundialización parece imponer una perspectiva cortoplacista que viene de la mano de la obsesión por la comunicación en "tiempo real". La ética, la política y hasta la filosofía parece que tienen que limitarse para "tocar la realidad" a resolver cuestiones inmediatas. Como Jerôme Bindé señala: "A la tiranía de la inmediatez, que sirve de excusa al 'después de mí el diluvio' de los príncipes, responde la tiranía de la urgencia". Esta va acompañada de la desaparición acelerada de la idea de un proyecto colectivo. No logramos ya proyectarnos en el marco de una perspectiva a largo plazo. Desde este punto de vista, la urgencia es "una manera de destruir el tiempo, una negación activa de la utopía"'. Y esta lógica de la urgencia dista mucho de ser un mecanismo transitorio. Más bien se hace permanente, de modo que tenemos la sensación de estar viviendo en estado de emergencia. Frente a esta situación es importante tratar de detenernos y hacer el esfuerzo por pensar las alternativas. La visita del profesor Franz Hinkelammert a la $\mathrm{UCA}^{2}$ ha representado para un grupo, entre el que he tenido la suerte de contarme, una espléndida ocasión para reflexionar y tratar de poner en claro algunos temas sobre este estado de cosas que todos lamentamos. La propuesta de reflexión la hace un profesor de economía que se mueve a caballo entre ésta y la filosofía. Las recoge una estudiante de filosofía preocupada por hallar en las ciencias sociales algunas luces que ayuden a abrir nuevas perspectivas y por compartir con las lectoras (es) algunos puntos de esta reflexión.

\section{La situación moral de nuestro tiempo}

A estas alturas del siglo, una parte de la humanidad tiene el sentimiento de no haber habitado nunca la tierra, de no conocer a los suyos ${ }^{3}$, sentimiento de desarraigo del apátrida que dejó de creer en la historia porque ha jugado a la humanidad demasiadas malas pasadas. Como resultado de esto, la civilización blanca y primer mundista tiene un "deseo de ser piel roja", una necesidad imperiosa de sentirse vivida, de superar el sinsentido, pero lo que experimenta es la soledad del desierto de hormigón al que está quedando reducida la tierra y la sequedad del propio cuerpo bajo el efecto de la sofocación de la sensibilidad que la vida moderna

1. Bindé Jérôme y cita a Laidi Z., La Prensa Gráfica, San Salvador, 8 de diciembre de 1997.

2. Con ocasión de un curso del doctorado en Filosofía Iberoamericana durante la segunda quincena de septiembre sobre el tema "Alternativas al capitalismo".

3. Morey Miguel, Deseo de ser piel roja, Anagrama, Barcelona, 1995. 
ha dejado en su mínima expresión. Esto por lo que respecta al cuarto de humanidad que come tres tiempos al día y tiene acceso a la educación y a lo que se entiende por una "vida humana digna". Esta porción de humanidad se halla desesperanzada. El resto, los otros tres cuartos, padece un problema muy otro, se trata de la desesperación. El desesperado es aquel al que han arrebatado todos sus derechos, empezando por el derecho a la vida; y la restitución de éstos no depende para nada de su esperanza. Esta desesperación no es un estado mental, sino un lastimoso estado material que alcanza a millones de personas. El desesperanzado es el que ha tenido una esperanza, el que ha sido optimista y cuando la realidad ha cuarteado sus angélicas creencias se ha sumido en la desesperanza. El desesperado, en cambio, para salir adelante no necesita sólo cambiar su estado mental, sino un estado de cosas que afecta a su rcalidad entera.

En el plano moral, los posmodernos sostienen que no hay ética posible después de Auschwitz. Vendría a ser la expresión en ética de lo que son en física las teorías del caos. Se trata en el fondo de la afirmación de que no conocemos nada, y que lo mejor que podemos hacer es reconocerlo. Sin embargo, si bien estas teorías aportan algo de verdad porque apuntan al hecho de lo limitado de nuestro conocimiento y a la imprevisibilidad del producto de nuestras acciones, también conllevan una luerte carga emotiva. que es importante contrarrestar si pretendemos ponernos algún día en la Icsilura de intentar formular alternativas. "La postmodernidad se podría caracterizar culturalmente como una atmósfera de pérdida de confian- za en la razón. Los motivos de semejante pérdida pueden ser formulados teóricamente, pero sobre todo son vividos difusamente por el hombre de la calle, sobre todo por el joven"4. El posmoderno siente muy claramente que la vida es suspensión y emplazamiento, que por una parte no estamos determinados, pero que la vida es fugaz y algo hay que hacer. En la espera podemos estar como quien mira pasar nubes en el cielo y se percata de la importancia de este hecho porque en virtud de la muerte no nos será dado contemplar infinitas variaciones en la danza de las nubes; pero también hay un emplazamiento: o actuamos en consecuencia o el destino es inevitable. El sentido generalizado parece ser más bien el último, de ahí que para muchos no quede más alternativa que hacerse a la idea de que la dirección está tomadas.

\section{Amenaza mundial o posibilidades globales}

Frente a esta postura generalizada en el primer mundo y que Hinkelammert ilustra con la imagen de La Marcha de los Nibelungos ${ }^{6}$ cabe decir que en el Auschwitz en que se ha convertido el mundo, no todos están de acuerdo en que no queda otra alternativa que morir. Precisamente una de las grandes enseñanzas - si es que así se pudiera hablar de algo que se aprendió a tan alto costo- del holocausto es la inmensa resistencia, creatividad y amor a la vida que muchos de los condenados desarrollan y que cuestiona la "mística de la muerte" que forma parte de la estructura de lo trágico". Cabe, sin embargo, preguntarse si hay otra forma de ser humano más allá de lo trágico, es decir, que si cabe ceder a la atracción del abismo ${ }^{\text {* }}$ tambićn

4. Martínez Cortés Javicr, Modernidad y Postmodernidad (cuaderno de trabajo), Eugenio del Río (editor y comentarista), Talassa. Madrid, 1997.

5. Son posturas como la de Denis Meadow, coordinador del inlorme del Club de Roma sobre el crecimiento que aliirmaba "Suficiente tiempo he tratado de ser un evangelista global y he tenido que aprender que no puedo cambiar el mundo. Adenás. la humanidad se comporta como el suicida, y no tiene sentido argumentar con el suicida una vez que ha saltado por la ventana”. Der Spiegel, No 29, 1989, p. 118. Citado por Hinkelammert F., Cullura de la esperanza y sociedad sin exclusión. p. 168.

6. Hinkelammert Franz, Asesincato es suicidio (inédito), Curso UCA San Salvador, octubre, 1997.

7. Lo que muestra la tragedia es la necesidad del crimen y del sacrificio. "Como si el sacrificio fuera la forma inicial, sagrada del crimen (...). La latalidad del crimen es el centro de la tragedia, la tragedia misma". "Y diríase en cuanto al aspecto humano de la tragedia, que el hombre aparece como el criminal que va en busca del crimen. del crimen único que habría de apaciguarle y realizar su naturaleza". Zambrano María, El hombre y lo divino, Fondo de Cultura Económica, México, 1993, pp. 149 y 148.

8. "El vértigo es algo distinto al miedo a la caída. El vértigo significa que el abismo que se halla a nuestros pies nos atrac. nos seduce, despierta en nosotros el deseo de caer", Kundera Milan, La insoportable levedad del ser, ค. 58. 
es legítima -y posiblemente mayoritaria, o aunque no lo fuera sería por lo menos igual de legítima- la contraria, la que intenta formular que dado el estado del mundo, todavía podemos actuar en consecuencia.

Si optamos por la inevitabilidad del destino, no hay más opción que saludar al suicida cuando pase a nuestra altura y taparnos los oídos para no oír el gran estrépito. Es la postura del pesimista, del que cree que ya no hay nada que hacer. Pero si intentamos en cambio pensar que existe la posibilidad de actuar en consecuencia necesitaremos buenas dosis de entusiasmo, que es el estado vital que se encuentra entre el optimismo y el pesimismo. "Ante todo, la vindicación de la idea de entusias. mo, planteándola en concreto, como engarce del querer, cl poder y el deber humano" "Necesitamos recuperar el entusiasmo para comenzar a pensar en las alternativas. No se trata del optimismo, pues el optimista es una persona que no quiere hacerse cargo de la incompletud de la condición humana, empezando por la suya propia. Como criatura de Dios y del Estado, también quiere ser omnipotente e inmortal. Lamentablemente ya hemos sido víctimas de las filosofías optimistas. De alguna manera todas las filosofías modernas lo son, y posiblemente por esta razón hoy día se halla tan en boga la conciencia trágica, que es hija de un pesimismo ontológico. Frente a ambos -optimismo y pesimismo-, el entusiasmo supone una vocación de intervención en lo real, y permite ligar el querer humano, lo que deseamos en primera instancia, con lo que podemos y con lo que debemos en los ámbitos del saber, del hacer y del esperar. Es también un sentimiento de afirmación vital, pero no un sentimiento que es azar arbitrario o gracia otorgada, sino pasión que se constituye alrededor de un proyecto y una memoria. El entusiasmo sería pues la energía y la alegría orientada a un fin, sería una de las conexiones entre teoría y praxis.

El intento de vuelta a las raíces plasmada en los típicos productos culturales de nuestra sociedad industrial (new wave, auge del esoterismo, de la magia,...) no es más que la muestra de un sentimiento de pérdida que por medio de ciertos tipos

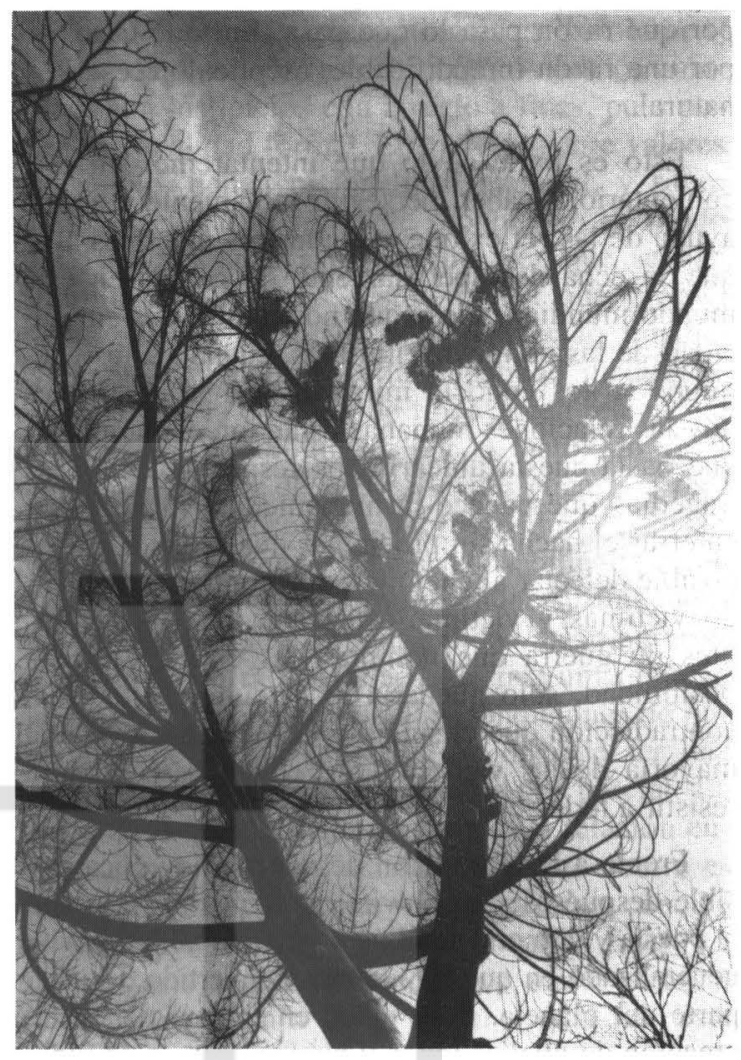

de conocimiento, pretende salvarse de las desilusiones a las que nos ha llevado la razón moderna. La civilización occidental, blanca y primermundista, se siente condenada a vivir una existencia póstuma"'10. Como se ha perdido la esperanza en el mundo y la humanidad se dedica al carpe diem más inmediatista y renuncia a actividades más a largo plazo porque desconfía totalmente del futuro. Hay motivos para pensar que el mundo se está convirtiendo en un gigantesco campo de concentración, pero aun si esto fuera cierto, la poesía y la moral no serían sólo posibles, sino más necesarias que nunca. Afirmar lo contrario sería como decir que la historia no tiene remedio, sería tanto como alistarnos tontamente a "las milicias del Señor de Turno, de los arcángeles de la desolación emplazados a anunciar que el que viene es quien tiene que venir, y que lo que pasa, pasa siempre por alguna razón"l'. Hay que analizar cuidadosamente

9. Stratós Jorge, "Contra optimismo, entusiasmo", pp. 40-42; Página Abierta, No 73, 7 junio de 1997.

10. Morey Miguel, Op. cit.

11. Morey Miguel, Deseo de ser piel roja, p. 38. 
por qué razón pasa lo que pasa. En todo caso, no por una razón inmodificable, aséptica, necesaria y natural.

Esto es parte de lo que intentaremos en este comentario, a saber, perseguir tercamente y con la ayuda de las reflexiones de nuestros maestros algo que se echa desesperadamente de menos en este mundo mundializado y que nos remite a la simplicidad de las culturas primitivas, cuando a los enemigos se los conocía mirándolos a la cara, pues hoy las relaciones humanas están tan enmarañadas que hasta cuesta ubicar a los responsables de las tragedias que padece la humanidad. No podemos enterrar el hacha sin proclamar que todavía hoy es posible detectar al enemigo, que continúan habiendo víctimas y victimarios, y que hay unos nombres de guerra que nombran las cosas. Sin esta posibilidad, sólo quedaría el suicidio, y se da la contradicción que el suicidio no es la opción de la mayoría de las víctimas que eligen casi siempre resistir a toda costa.

Frente a la afirmación de que no hay ética posible después de Auschwitz, podemos afirmar que la poesía y la moral son la única salida al Auschwitz generalizado en que hoy hemos convertido a buena parte del planeta. Sólo ellas, en lo que tienen de creación de nuevos logos y nuevas formas de vida, son capaces de hacernos habitar el presente, un presente que se vive bajo el signo de la amenaza porque nos damos cuenta que al tratar la tierra como objeto de conquista nos destruimos a nosotros mismos. No se trata de una cuestión de gustos o sentimientos, sino del hecho de palpar la erosión de las condiciones de posibilidad de la vida humana. El crecimiento ilimitado es suicidio, como señaló ya el informe del Club de Roma en 1972. Con nuestros modos de vida estamos asesinando la tierra y suicidándonos a nosotros mismos, pero con la mundialización el problema se agudiza más si cabe, puesto que los procesos se vuelven mucho más complejos, a la vez que afectan a todos. En virtud de la mundialización se da la situación de que las acciones de unos tienen repercusiones en las de otros situados a miles de kilómetros de distancia. Pero tenemos que analizar el hecho con cuidado: si bien es cierto que el tedio de los que hacen fila para ver la última producción de Hollywood está directamente relacionado con la fila en un campo de refugiados en cualquier país de Africa, también es cierto que la constatación de esa relación no nos puede llevar a afirmar que ambas vidas son lo mismo. Ni la vida es la misma, ni los sentidos, ni los pensamientos, ni los sentimientos ni las responsabilidades. Por esto no nos es permitido asumir el "da igual". Por otra parte no hay una isla en la que podamos refugiarnos. Como advierte Hinkelammert: "el proceso de globalización del mundo (...) es un proceso del mundo real, cuyo resultado es la experiencia de una amenaza global que solicita una responsabilidad global".

El problema es que la amenaza no se experiencia, sino que sólo se concluye por la razón. En cambio si se experiencia que nuestras casas son cada vez más limpias mientras que el entorno es cada vez más sucio, que el aire se ha vuelto irrespirable, que cada vez surgen enfermedades nuevas con mayor velocidad. Todo esto nos puede llevar a sentirnos amenazados, pero no todos se sienten así: unos se sienten mal y otros se sienten más felices, seguros y cómodos que nunca. De ahí que sea tan importante el ejercicio de la razón, pues una amenaza es un tipo de "experiencia" que consiste en sentir la inminencia de un peligro seguro.

El proceso de mundialización ${ }^{12}$ es efectivamen-. te un proceso del mundo real que contiene una amenaza. Ya que no somos capaces de instituir el

12. Respecto a la palabra "globalización" nos parece más adecuado el uso del término "mundialización", cfr. José María Vigil, Agenda Latinoamericana. "The globe" en inglés no significa cualquier globo, sino "el globo terráqueo" por antonomasia, de modo que cuando en inglés se habla de lo global se está hablando invariablemente de algo relativo al globo terráqueo, al planeta, al mundo. Por eso en inglés "global" es sinónimo de "planetario", "mundial". En español, por el contrario, "globo" no es una forma de referirse a la tierra; para hacerlo hay que aludir al "globo terráqueo". Por otra parte, "global" puede referirse a muchos niveles distintos, sin implicar primariamente el nivel planetario: se puede hacer, por ejemplo, un presupuesto global a escala personal, familiar, de una empresa, nacional, y claro está, también del mundo, pero en todo caso hay que especificarlo; no es algo que se pueda dar por supuesto, como en inglés. Usarlo en este sentido es un anglicismo. Los diccionarios dan definiciones del tipo mundial: (adj.) perteneciente o relativo al mundo entero. 
bien común, ¿será el mal común el acicate para lanzarnos hacia nuevos derroteros? Si queremos escapar a la violencia universal, a la destrucción de la relación social que provoca la exclusión, ¿será la amenaza un revulsivo para el pensamiento y la acción? ¿O nos mostraremos como los personajes de Sartre en Huis Clos que ante el peligro común se muestran incapaces de pensar y actuar de otro modo que como átomos de egoísmo? Frente a esta idea se puede apuntar que la amenaza no es lo único que surge. Al mismo tiempo que ésta, hay unas posibilidades globales que se pueden hacer surgir. Intentar dilucidar cuales serían estas posibilidades sería un camino para enfrentar la "míslica de la muerte". Si bien hay que reconocer que existe esta mística, y que es difícil de contrarrestar, también es cierto que pensarlo únicamente como amenaza produce espanto, paraliza. Sin negar la amenaza, tenemos que analizar qué posibilidades hay, por dónde pasarían las alternativas.

Hay que hacer un llamado a la prudencia: no podemos correr riesgos que lleven a fracasos estrepitosos, pero por otra parte tenemos que pensar que queda suficiente cordura a la humanidad como para reaccionar. Cabe esperar la reacción, porque los males son males para todos. Como decíamos, no existe una isla en el universo donde nos podamos salvar. En este sentido, es condición de posibilidad para tratar de ejercer la racionalidad el no asumir la postura de que ya nos hemos tirado por la ventana. Estar amenazado no es estar perdido.

\section{La teoría de la acción racional de Weber como exponente del capitalismo utópico}

Si queremos analizar como hemos podido llegar a parar a este estado de cosas o, incluso, como se ha podido pensar que toda esta locura se haya visto o se vea hoy día como "racional", tenemos que retrotraernos a una época anterior, al período en que se fraguó la mayoría de las concepciones que hoy manejamos, o por lo menos en el sentido en que hoy se manejan; léase racionalidad económica, producción, ganancia, trabajo, productividad, eficiencia y desarrollo económico. Una teoría ilustrativa en este sentido y que Hinkelammert analiza en Crítica a la razón utópica y más en detalle en El mapa del Emperador, es la teoría de la acción racional de Max Weber.
Para Weber, hay que distinguir cuidadosamente entre medios y valores. Los únicos juicios científicos son los juicios con arreglo a fines, pues poseen racionalidad formal. Los juicios sobre valores en cambio, tienen racionalidad material, y sobre ellos la ciencia no se puede pronunciar, de modo que ésta comienza a actuar una vez que se han determinado los fines. Esto implica que propiamente sólo es racional, o lo que es lo mismo, evaluable racionalmente, la linealidad medio-fin, mientras que la elección de fines queda relegada a la subjetividad o voluntad, por lo tanto, sin valor objetivo. Se trata de una reflexión ética que pretende superar la convicción (individual) para situarse en el terreno de la responsabilidad, ahora bien, lo que consigue, como denuncia Hinkelammert, es caer en la irresponsabilidad más flagrante, pues limitar la racionalidad a la instrumentalidad dejando a la buena de Dios las condiciones de posibilidad de la vida humana, no deja de ser una responsabilidad bien irresponsable por parcial. La teoría de la acción racional elimina la relación entre los fines y la vida del actor. Lo que ocurre es que esta teoría presupone fines parciales, concibe un escenario en el que compiten varios fines. La ciencia sería aquella instancia que omite efectuar cualquier decisión a favor de tal o cual fin. Esta decisión caería dentro del terreno del juicio de valor, mientras que lo propiamente científico sería ocuparse de la relación medios/fines, mientras la ética se ocuparía de la escogencia de fines. Con ello, Weber pretende dirimir, deslindándolas de una vez por todas, las pretensiones de ciencia y ética.

Contra este planteamiento, Hinkelammert señala que los criterios que envuelven la vida y la muerte no son falsables, pues su falsación implicaría, como él irónicamente señala, una contradicción performativa. Con una imagen bien gráfica subraya que "somos como dos competidores que están sentados cada uno sobre la rama de un árbol, cortándola. El más eficiente será aquél que logre cortar con más rapidez la rama sobre la cual está sentado. Caerá primero, pero habrá ganado la carrera por la eficiencia" ${ }^{3} . ¿$ Cuando se trata de este tipo de eficiencia y racionalidad podemos decir que es eficiente y racional o más bien cae en la irracionalidad? Una racionalidad de este corte, en-

13. Hinkelammert F., El mapa del emperador, p. 13. 
cerrada en la linealidad medio-fin, no puede siquiera dejar una apertura para previas o ulteriores discusiones tales como qué rama cortar. Una concepción tan estrecha y cerrada no deja engarce posible con lo que rodea a la relación medio-fin, como son las condiciones de posibilidad o las consecuencias de la acción. El resultado es que con este tipo de análisis se mistifica buena parte de la realidad. Es como si proporcionara una foto fija del status quo, de los cortadores de leña, según el ejemplo, pero es un tipo de análisis que no permite ir más allá: ni hacia el pasado ni mucho menos hacia el futuro. Es el afán de aprehender las cosas en su quietud lo que hace que salgan deformadas, lo que nos hace caer en la "irracionalidad de lo racionalizado".

No es que la racionalidad medio-fin no sea sumamente útil en muchos casos, sino que al totalizarla, al analizar toda realidad en esta forma de racionalidad, constatamos que esta es parcial. Al presuponer que el único criterio es el de falsación/ verificación, dejamos de lado un sinnúmero de criterios, como los de vida/muerte, que no son falsables, puesto que conllevarían la destrucción del propio actor. Una salida a este dilema, como apunta Hinkelammert, sería tener presente que, previo al criterio de verificación/falsación de Popper $^{14}$, hay que enfrentar la cuestión de la racionalidad reproductiva ${ }^{15}$, como ya advertía el sabio Marx. Una racionalidad que no tome en cuenta esta racionalidad reproductiva es irracional por parcial.

\section{Eficiencia y racionalidad económicas en el capi- talismo}

$Y$ es precisamente este tipo de racionalidad el que fundamenta el concepto de eficiencia y racionalidad económicas que sumen al mundo en la destrucción ambiental y la pauperización a una parte creciente de la población. Se trata de unos conceptos de eficiencia y racionalidad que ocultan el hecho de que estamos destruyendo las bases de nuestra vida ${ }^{16}$, de ahí que sean altamente cues- tionables. El cálculo de eficiencia se logra mediante la comparación de medios y fines. Se trata una vez más de un concepto que pretende ser puramente económico: se refiere al cálculo de los costos de los medios en relación con el fín a lograr. Supone que tanto los fines como los medios se pueden expresar en términos cuantificables, y se dice que hay eficiencia si se consigue el fin empleando medios cuyos costos son de menor precio que el fin alcanzado. Esta concepción de racionalidad como cálculo monetario de costos para producir un fin es la que apadrina el concepto de economía basado en un juego de suma cero.

El problema es que, como señala David Schweickart, los economistas tienden a hablar de eficiencia económica como si se tratara de un concepto neutro, pero no lo es. El concepto de eficiencia económica es un valor tanto como lo son la libertad e igualdad. Se puede lomar la palabra "eficiencia" en un sentido neutro o instrumental para designar sencillamente la "producción de un efecto deseado", pero hablar de "eficiencia económica" implica mucho más ${ }^{17}$. Este concepto no puede reclamar para sí una inocencia normativa pucsto que presupone una o varias opciones éticas. Supone, en primer lugar, que lo que manda es el precio (valor monetario) y, en segundo lugar, obvia que caben varios conceplos de eficiencia, así como de justicia. En la sociedad moderna, y a partir de la tcoría neoclásica, el concepto de eficiencia está basado fundamentalmente en el concepto de producción de bienes materiales con el mínimo gasto de trabajo y recursos y el sentido más técnico del Optimo de Pareto (un estado de cosas en el que no se puede realizar un movimiento para mejorar la situación de unos sin afectar el bienestar de otro).

Pero demos otro paso más atrás en la historia y pasemos revista a otros términos como los de producción y crecimiento. Nos percataremos de que en una fecha tan próxima como el siglo XVIII no existían $^{18}$. En aquellas fechas, estas cuestiones estaban ligadas ineludiblemente a la moral, como lo

14. En Crítica de la razón utópica, DEl, San José, 1984, Hinkelammert analiza a Popper como exponente de razón utópica. Este autor a pesar de su crítica cae en una ingenuidad utópica. Lo mismo ocurriría con Weber cuyo pensamiento analiza más en detalle en el Mapa del Emperador.

15. Hinkelammert Franz J., Crítica a la razón utópica, Dei, San José, 1984, pp. 21-27; y El mapa del emperador, DEI, San José, 1996, pp. 14-31.

16. Op. cit., cap. 1, pp. |1-41.

17. Sweickart D., Against Capitalism, p. 78.

18. Naredo José Manuel, “La mistificación del lenguaje económico", Página Abierta, Madrid, febrero, 1997, p. 41. 
había estado en su tiempo la política antes de que Maquiavelo la emancipara. Pues bien, uno de los efectos de la autonomización de la economía consiste en la consideración de que las riquezas se consideren algo deseable de por sí y que, además, se quieran incrementar permanentemente. "La propia noción de riqueza sufre un desplazamiento, desde una visión diversificada, en la que predominan los bienes raíces, hacia una noción homogénea, en la que el dinero lo invade todo y se acaba identificando con la riqueza. En cualquier caso, ese aumento sin fin de riquezas es un objetivo insólito en la historia de la humanidad. Es un cambio importante, pero luego, la segunda condición es que se considere posible acrecentar estas riquezas, porque hasta entonces se pensaba que el hombre no podía intervenir de forma significativa en los ciclos de la Naturaleza"1".

Esas riquezas venían como fruto de un maridaje entre el cielo y la tierra; se podían cmular mediante el rito, pero no se podían acrecentar de forma permanente. Sin embargo, con la moderna ciencia experimental, se cree que el hombre sí puede intervenir en los ciclos, colaborar con la Naturaleza para que crezcan estos frutos de modo permanente. (...) De lo que se Irata es de acrecentar las riquezas renacientes sin menoscabo de los bienes fondo. Esto es lo que decía Quesnay, el jefe de filas de los economistas franceses del siglo XVIII, que es el pionero creador de esta noción de sistema económico (...) Pero poco a poco la noción de producción acaba conviertiéndose en una idea que define producir como revender con beneficio, en el sentido de que las unidades de medida no son más que el valor añadido o producto nacional. Es decir, valor en venta del producto menos el valor de las compras necesarias para obtenerlo: un saldo meramente monetario. Este sistema económico que nació en cl mundo físico se traslada así al universo autosuficiente de lo pecuniario, y el carrusel de la producción y del consumo gira ya permanentemente en ese campo pero, ia costa de qué? Pues a costa de ocultar lo que es adquisición de riqueza, porque parece que ya todo el mundo produce en beneficio de todos, y ya no es un problema moral el reparto, que es lo que preocupaba con anterioridad [a los escolásti$\cos ]^{20}$.

El resultado de todo esto es que una realidad compleja (naturaleza, producción, bienes) se reduce a unas cifras expresables en una única unidad: la monetaria, y de la mano de la producción viene la idea del crecimiento como algo positivo para la humanidad. Se trata de un esquema que tiene su propio ímpetu, que una vez se impone es difícil de parar. Las adiciones lentas y casi desapercibidas se suman finalmente para construir un concepto de racionalidad que nos deja sin otra alternativa que la de aceptar en conjunto lo que hemos aceptado previamente por partes. Todas las actividades irán llamándose gradualmente "productivas" encubriendo la destrucción que originan a todos los niveles. "Por otra parte, la idea de crecimiento, cuando comienza a hacer agua porque parece que crea ciertos desequilibrios y problemas sociales, se abandona y se emplea entonces ese otro término más ambiguo de desarrollo. Y luego, si preocupan los temas medioambientales, ecológicos, etcétera, se refuerza con el adjetivo de sostenible, para seguir empleando la misma noción que mantiene esa síntesis" ${ }^{\prime \prime}$.

La paradoja que se da es que precisamente en el momento de la historia de la humanidad en que se extraen masivamente los depósitos minerales de la corteza terrestre (la extracción de combustibles fósiles supera en tonelaje a los productos derivados de la fotosíntesis hoy día), en este mismo momento se acuña en economía el término encubridor de "producción", para aludir no ya principalmente a un proceso que atañe mayormente a los productos derivados de la fotosíntesis, que sería su sentido clásico, sino para referirse a procesos que ocasionan un irreversible deterioro ecológico, que permanece oculto gracias a una crasa mistificación.

19. Ibid.

20. Ibid.

21. Ibid., p. 42. 
De la racionalidad de lo irracional: el capitalismo cínico

Con Weber descubrimos una racionalidad utópica $^{22}$ que se convierte en "irracionalidad de lo racionalizado" ${ }^{23}$, en virtud de la totalización de uno solo de los aspectos de la racionalidad como es la linealidad medio-fin en ética o el mercado en economía. Sin embargo, la perplejidad no se detiene ahí. Resulta que ésta es la posición del sistema a comienzos de siglo. Ahora, lo que encontramos ya no son planteamientos utópicos sino cínicos como los de AlvinToffler ${ }^{24}$. Sus descripciones son veraces, no miente, es descriptivo y no sacraliza el status quo apelando al interés general sino a la aceleración de la máquina de bienestar. La legitimación se realiza por medio de la celebración de la velocidad ${ }^{29}$. Según Hinkelammert, frente a este tipo de legitimación no procede la crítica a la ideología, porque no hay núcleo racional común que permita apelar a juicios de hecho para mostrar que lo que el sistema dominante postula no se cumple en realidad. No hay funcionamiento engañoso que desenmascarar para poner en evidencia la contradicción de la teoría dominante, porque ésta dice sin tapujos lo que hace. La razón moderna, que antes era utópica, se ha vuelto cínica. Omite ya cualquier referencia al "interés general" y nos espeta provocativamente "sí, ¿y qué?" „a

Lo que caracteriza al capitalismo cínico es su asunción de que no hay alternativa, y que "lo que es eficaz es necesario y bueno". Esta glorificación del presente no percibe ninguna amenaza, con lo cual se entroniza lo que Hinkelammert llama la "dinámica del torturador" expresada por las palabras del general Massis en la guerra de Argelia que decía: "la tortura es eficaz, por lo tanto es necesaria". Nuestra civilización dice: "el progreso es eficaz, por lo tanto es necesario". Dicha lógica implica llevar a las relaciones humanas y la naturaleza hasta el límite de lo aguantable. Como no interesa pensar alternativas, y como al fin y al cabo hasta el más despreocupado advierte que es necesaria una cierta dosis de moderación, se produce una reacción que dice: "no debemos sobrepasar el límite" ¿Qué tenemos que hacer entonces? guerras de baja intensidad, poner a circular siempre más carros pero con gasolina sin plomo, usar sprays que no afectan la capa de ozono, etc. ${ }^{27}$ Los cálculos sobre el límite de lo aguantable sobreentienden que se puede ir hasta el límite. El mito del cálculo se basaría en creer que hay un límite de lo aguantable, límite que sólo se conoce cuando se ha sobrepasado. El mito consiste en la locura de tratar de mejorar el cálculo para no pasar el límite. Es el extremo del cinismo, el cinismo funcionando prácticamente frente a la naturaleza y la humanidad. El sistema nihilista no se alarma si se sobrepasa el límite, puesto que su horizonte es la muerte, tiene hacia ella una irresistible atracción, y la marcha que hacia ella realiza es interpretada como "realismo". Es el núcleo de la conciencia trágica: hay un destino que nos lleva a la muerte, y hagas lo que hagas da igual porque es ineludible. Cualquier intento de escapar de él es vano.

El problema para Hinkelammert es que frente a la ideología estaba la crítica de la ideología pero, ¿cómo hacer una crítica del cinismo? Creemos que el cinismo también tiene su racionalidad y puede que también un profundo sentido moral, como lo puede tener el suicida. Uno puede tener poderosas

22. Hinkelammert, Crítica a la razón utópica, p. 25.

23. Mapa del emperador, p. 29.

24. Powershift, knowledge, wealth and violence at the edge of the 21 century Bantan Books 1991.

25. Asesinato es suicidio, p. 6. Por cierto, podríamos preguntarnos por qué la velocidad es tan atractiva que hace que hasta un monje del siglo XII la incluya en la descrición de los gozos del cielo, cfr. San Anselmo de Canterbury, Monologion.

26. El cinismo afirma "lo que es es lo que debe ser" ${ }^{2 \hbar}$. Se celebra la "destrucción creadora". El capitalismo utópico se ha vuelto nihilista, ya no contradice a ningún potencial de razón porque no reclama ninguno y "donde no hay ninguna pretensión de la razón los juicios de hecho, que demuestran la sinrazón, dejan de tener ninguna capacidad crítica. Si ya no se pretende una razón de interés general, los juicios de hecho que desenmascaraban al capitalismo utópico mostrando que no realizaba ningún interés general quedan sin potencial. La destrucción y cxclusión que produce el capitalismo no puede ser enfrentada racionalmente porque no hay hipocresía. El copitalismo ha renunciado a su "rostro humano", del cual ahora se burla.

27. Hinkclammert, Asesinato es suicidio, p. 5 (inédito). 
razones para suicidarse, y uno puede cometer suicidio sin dejar de tener una altura moral. Sin embargo, matar a los demás ya es otro asunto porque con esta acción estoy obviando el hecho de que los demás puedan disentir, y porque si lo hacen ya no estoy aplicando la razón, sino la fuerza.

Al pensar en las alternativas no podemos dejar de analizar esta racionalidad del cinismo que es digna de ser tomada en consideración; en primer lugar, porque es una postura sumamente extendida; en segundo lugar y más importante, porque con todo lo negativo que pueda tener sí que denuncia los hechos, y esto puede ser un punto de partida importante. Frente a una racionalidad que se mueve en el mundo de las ideas como era la razón utópica, ésta tiene la ventaja de decir lo que pasa y esto ya despeja bastante el terreno pues nos evitamos todo el rodeo de la crítica. Al que pretende arrastrarnos al suicidio le podemos decir: "váyase al hoyo usted solito, y si pretende matar la tierra no cuente conmigo porque de ella vivo". Hay un núcleo de razón que consiste en decir "yo no me quiero morir o no quiero matar". La alteridad es ineludible e irreductible. Pero así como tiene un núcleo racional lambién tiene un núcleo sentiente. El cinismo es ante todo un sentir, y un sentir del descalabro que se siente también y máximamente en el primer mundo. Tanto el escéptico como el cínico tienen posturas refutables. El cinismo es una postura refutable como la del escéptico porque no se autosostiene sino con la afirmación de que todo es relativo a un absoluto que no exisle (sea éste la muerte, el destino o el infierno). Sin duda se le pueden oponer razones, que seguramente no serán consideradas, pero también queda la fuerza en sentido maquiavélico: valorar nuestras posibilidades de acción, tener reacciones rápidas, pues al fin y al cabo los que no son cínicos son la mayoría, y vencerlos o contrarrestar su poder puede que no sea imposible, aunque sea difícil. En este sentido, estaríamos intentando esbozar una política en el sentido más clásico, como ciencia de lo posible.

Hinkelammert levanta aquí la cuestión de la le- gitimidad: El sistema se legitima cínicamente. Per a Hinkelammert es molt important la legitimació, jo crec que no, en este sentido creo que es rescatable no el cinismo, pero sí el cierto pragmatismo en que incurre la posmodernidad cuando se niega a anclar los relatos de verdad y justicia en los grandes relatos históricos y científicos ${ }^{2 \mathrm{R}}$. Hay que tomar nota de lo que hemos aprendido en siglos de modernidad, $y^{\prime}$ es la distancia que media entre un proyecto con tantas promesas de emancipación que haya llevado a la humanidad a situaciones tan contrapuestas con respecto a las promesas programáticas. Tal vez parte de estos errores se esconden en el esfuerzo de concentración sobre la legitimación (hacer el mapa, dar las razones para hacerlo), dejando de lado la más inmediata realidad que acaba por ser opacada. En el estado de la cultura en que se mueve la posmodernidad se observa la imposibilidad de establecer discursos de legitimación, y ésta sería parte de nuestra "condición" actual ${ }^{24}$. Esto no significa renunciar a la fundamentación, pero hay una diferencia entre ésta y la legitimación. La primera puede ser abierta, mientras que la legitimación no.

\section{Razón sentiente y búsqueda de alternativas}

Dentro de este marco tenemos que romper una lanza a favor de la ciencia. Para Hinkelammert, la lógica de la ciencia desde Bacon ha sido la dinámica de la tortura, pero nosotros seríamos más moderados a la hora de hacer valoraciones de la ciencia, pues si bien es cierto que está bien dicho como expresión crítica que la ciencia no es neutra y puede resultar bien totalizadora, así como la globalización es un hecho, la ciencia también es un hecho con el que debemos contar. Hinkelammert distingue en la globalización el hecho y la estrategia, también cabría señalar lo mismo en la ciencia: lo que es la ciencia como marcha de la razón hacia lo profundo de lo real y la ciencia como su uso social. La expresión "torturar hasta el límite sin pasarlo para que se suelte un secreto. Eso es occidente desde Bacon" es demasiado apocalíptica.

Este mundo anda mal, pero seguramente no es

28. Lyotard Jean-Francois, La condition postmoderne, París, Ed de Minuit, 1979, p. 7.

29. "Nuestro siglo ha visto cómo el paŕs de mayor nivel cultural de Europa desembocó en Auschwitz, cómo el país que representaba la alternativa al orden constituido dio lugar al Goulag, y cómo el desarrollo científico-lécnico de Estados Unidos vio su luminosa culminación en Hiroshima", Urdanibia Iñaki, " ¿Postmodernidad ha dicho...?", Página Abierta, abril, 1997, No 71... sin mencionar otras tantas catástrofes del siglo... 
el peor de los mundos posibles. En este sentido, y no para eximirlo de culpa sino para evitar caer en posturas irrealistas o paralizadoras, tendríamos que ponderar con más calma los recursos culturales de occidente. Puede ser que encontremos en ellos cosas bien laudables, tanto en la ciencia como en el cristianismo como en ciertas tradiciones políticas. No olvidemos que declaraciones como la de los derechos humanos, aunque conculcados hasta la saciedad, también son invento occidental. Antes de descartarlos totalmente podemos encontrar recursos que puedan ir a favor de las mayorías. El mundo del presente necesita una ciencia responsable, pero ciencia al fin y al cabo, y no sólo de las ciencias empíricas, sino de las ciencias sociales también.

Como ha mostrado Foucault ${ }^{\text {30 }}$, la razón moderna no es un solo tipo de racionalidad sino el conjunto de muchas racionalidades a veces contradictorias. Semejantemente podríamos decir que en la ciencia hay pluralidad de métodos, de prácticas, de objetivos. Lo mismo podríamos decir de la economía o la política. Pensar las alternativas no puede implicar condenar el mercado, la ciencia o la economía como unidad. Pensar seriamente las alternativas conlleva reflexionar qué hacer para que vaya mejor cada una de estas esferas, para que sirva a las mayorías. Para Hinkelammert: "el método cienlífico usual se encuadra a la perfección en esta globalización. No proporciona sino conocimientos aprovechables en el ámbito comercial. No puede proporcionar otros conocimientos, porque su propio método no le permite siquiera conocerlos. Consiste en hacer abstracción de la globalización del mundo real y por tanto de la realidad como condición de posibilidad de la vida humana, y por tanto, el conocimiento del mundo globalizado real se le escapa"'. . Lo que ocurre es que este tipo de racionalidad, como el concepto de economía que proponen, está viciado de raíz como bien señala Hinkelammert. Pero puede ser que examinándolo de cerca, incluso ahí encontremos elementos emancipadores.

Igualmente habría que matizar bastante la afirmación de que "lo que da carácter de guerras mundiales a las guerras que siguen a la colonización es el hecho de que el mundo esté dominado por un solo poder" 32 pues pensar el poder como único, ya se trate del poder del mercado, de la cultura estadounidense o del poder económico en general, más bien oculta que expone los diferentes planos, situaciones y estrategias en las que se ejerce el poder. El poder es múltiple. Lo que le da la cara totalitaria o monolítica es el peso con el que cae sobre la víctima, sobre quien no tiene maniobra de acción. Pero el poder no es nada, mucho menos una unidad. Anatemizar el mercado o la ciencia sería caer en la misma totalización o abstracción que aquella en la que caen los que las sacralizan, sería dejar de ver las raíces profundas de lo que es cada una: esferas de la actividad de los seres humanos concretos en su doble e indivisible dimensión corporal y espiritual que en su interrelación crean espacios, realidades nuevas, reproducen otras. Negar la economía o el mercado sería caer en una utopía peor, en la que ciertamente no cae Hinkelammer ${ }^{33}$.

También a la palabra "utilidad" le ha ocurrido lo mismo que a otros términos como placer o po-

30. Foucault, Les mots et les choses Gallimard, París, Nrf 1966 y Tecnologías del yo, p. 97.

31. El mapa del emperador, p. 6.

32. Asesinato es suicidio, p. 2.

33. Semejantemente habría que matizar la afirmación de que "nuestra vida se ha globalizado de una manera nueva", como nunca antes había ocurrido en la historia humana. Tenemos que analizar con detalle qué se ha mundializado exactamente. Si bien es cierto que hoy día nuestras acciones tienen un alcance planetario (la emisión de gases, la deforestación, tienen efectos que sobrepasan ampliamente el ámbito local en que se producen), no podemos decir sin más "estamos globalizados" porque lo que se ha globalizado son aspectos muy determinados como son las relaciones mercantiles, los transportes, los efectos nocivos de la contaminación atmosférica... Hay que analizar a qué niveles se han mundializado las acciones. Este análisis puede ser muy fecundo para comenzar a dibujar alternativas. Decir "nuestra vida está globalizada" es una verdad a medias. Desde el punto de vista del oprimido puede ser que la vida esté menos mundializada que nunca. Nunca como antes ha habido tantos miles de gente confinada en campos de refugiados, nunca antes ha habido tantas dificultades legales para la libre movilidad de las personas. Aunque esto sea también efecto de la mundialización, no lo es sin más. 
der. El temor a la absolutización ha hecho que desaparezcan lastimosamente del mapa. "Utilidad", "cficacia", no significan nada si no es con relación a lines. Picnso que sería más directa la crítica a la ćlica que se guía por el mero cálculo de utilidad mostrando sencillamente -como hace Hinkelammert- que un cálculo que no tome en cuenta las propias condiciones de posibilidad de reproducción de la vida, es contradictorio, como cuando nos damos cuenta de que estamos aserrando la rama en la que estamos sentados.

No se trataría de cuestionar el concepto de utilidad, sino de reivindicarlo ampliándolo, haciendo que incluya variables que no pueden quedar hoy fuera, tales como la ecología o la calidad de la vida humana en el más puro sentido utilitarista. Porque con la utilidad o la eficacia ocurre lo mismo que con la razón. Se pucde decir en muchos sentidos, pero no podemos renunciar a todos ellos. Son conceptos positivos y práxicos que hay que reivindicar.

Las alternativas pasan por la formulación de una razón razonable a la altura de los tiempos, así como de una eficacia o una utilidad que no acaba enterrándonos a todos. Ya Aristótcles utiliza el término refiriéndose a tres clases de bienes: bien útil, bien deseable y bien honesto. El primero se persigue con el fin de lograr otro bicn. Sin entrar aquí a analizar la concepción aristotélica, tal vez valga la pena subrayar que "bienes útiles" son para Aristóteles bienes básicos, aquellos sin los cuales la persona no puede conseguir los otros que el Estagirita considera "superiores". Son los bienes sin los cuales no es posible un bienestar. El utilitarismo no es una pura doctrina del egoísmo, sino que sus defensores ${ }^{34}$ deslacan la diferencia entre el utilitarismo vulgar y el filosófico, del que podemos extraer muchas y sensatas ideas. Bergson ha escrito que se requieren muchos siglos de cultura para forjar a un utilitarista como John Stuart Mill. Estos pensadores consideran que toda la vida humana está dominada por dos impulsos: el deseo de felicidad y la voluntad de evitar el dolor, hasta el punto que regir la sociedad consiste fundamentalmente en tener en cuenta tales impulsos. Conside- ran que la sociedad necesita urgentes reformas para promover el placer, el bien y la felicidad y evitar el dolor, el mal y la desdicha ${ }^{35}$, y la estructura política que ha de sustentar tales reformas tiene que ser liberal y democrática. Con el fin de elegir lo que es bueno es necesario establecer un cálculo de placeres y dolores que son juzgados según los siguientes criterios: intensidad, duración, certidumbre $o$ incertidumbre, proximidad o alcjamiento, fecundidad y alcance; esto es, el número de gente afectada ${ }^{36}$.

\section{Del "mapa del emperador" a "la lista del empe- rador"}

El instante parece destruir el tiempo. El hombre de hoy se otorga derechos sobre el hombre del mañana. Pero, ¿cómo reconstruir el tiempo a estas alturas de la mundialización? Vivimos en una especie de amnesia respecto al pasado y de una falta de perspectiva que nos dificulta la responsabilidad hacia el futuro. Hemos visto cómo, en cierto modo, esta miopía liene unos orígenes rastreables en la modernidad. La posmodernidad no ha realizado el tránsito. Para haccrlo tendríamos que lograr ser creadores de un liempo nuevo y un espacio nuevo, de crear nuevas experiencias puesto que todo vivir en el tiempo y la experiencia no es sino el conocimiento antes de ser universal. La posmodernidad es aún presa de la modernidad porque deambula todavía en la recreación de sus consecuencias, aunque veíamos también que puede representar un avance en ella, porque al pasar de la utopía al cinismo las cosas se han hecho más claras. En este sentido es como si volviéramos al tiempo en que a los enemigos se los conocía con sólo mirarlos a la cara ${ }^{37}$.

Tratar de elaborar un conocimiento que recoja la experiencia, siempre incompleto, siempre abierto, nunca definitivo, sería una de las tareas más urgentes que habría que acometer. La experiencia no pretende arrancarse del instante, no lo abandona como mera irracionalidad sino que extrae de su modesto logos su sentido, que no puede ser nunca completo ${ }^{38}$. La experiencia es siempre fragmentaria, pero puede apuntar no a la foto fija que veía-

34. Los principales son Jeremy Bentham, James Mill y John Stuart Mill.

35. Bentham Jeremy, An Introduction to the Principles of Morals and Legislation, cap. 1, sec. 3.

36. Ibíd., sec. 4.

37. Morey Miguel, Op. cit.

38. Zambrano María, La razón en la sombra. 
mos en Weber, sino a una razón dinámica, que dé cuenta del movimiento del pensar ${ }^{39}$.

Hemos visto cómo, en muchos aspectos, la razón moderna se ha dedicado a reducir, a negar, aun a anular sucesos, a hacer que lo que está pasando sea como si no fuera ${ }^{40}$. Pero este desencanto no puede degenerar en una desconfianza en la razón. De lo que tenemos que prevenirnos es de una razón que sea abstracción o totalización de un solo aspecto de la experiencia. "La razón ha de encontrar sus propios y adecuados movimientos a la situación: la razón vital, la razón viviente, la razón poética"41. Una razón a solas es locura. La razón instrumental es un tipo más entre otros muchos tipos de razones (razón seminal, razón de estado, ....). Se tratará de buscar una razón que no huya del sentir del que procede, pues él es quien moviliza la marcha de la razón, de buscar una razón que no lo sea de una realidad abreviada.

Como veíamos lo que hace Weber y aunque no nos hemos extendido en ello, la teoría neoclásica en economía es intentar adaptar la realidad a la pura conciencia racional, y a fuerza de hacer un esfuerzo por depurar el método, lo que nos dejábamos fuera no eran simplemente ciertos aspectos, sino la realidad entera. Se trata del mismo tipo de obsesión que la del emperador chino del cuento de Borges $^{42}$, que acaba empapelando el país con el empeño de su proyecto de realizar un mapa que represente exactamente todo su territorio $0^{43}$. Un mapa, para ser tal, necesita ser relativo. Pretender una mapa del imperio a escala natural no sólo es imposible porque no tenemos un conocimiento perfecto, o porque los costos sean incuantificables, sino simplemente porque comete la monstruosidad de sacrificar la realidad para construir una realidad virtual que es -obviamente - horrorosa porque está construida sobre el cadáver de la anterior. Se trata de un intento de envolver la infinita diversidad de lo real bajo el tenebroso espectro de lo mismo. La relatividad, en cambio, dice razón de otro, no necesariamente al modo levinasiano de una experiencia aleatoria en virtud de la cual me constituyo en rehén del otro, sino de un sentir o de una razón fundada en un sentir que no intenta borrar la alteridad que constituye su más profunda raíz, tanto de uno como de otra. Una razón sentiente no puede ser una razón de lo mismo, tiene que ser una razón que sigue el impulso de lo otro.

Ante el cuento chino del mapa del emperador, caemos ante la misma perplejidad en que nos tienen últimamente los biólogos con esta desatada afición a sacar monstruos de laboratorio. Primero una oveja clónica, luego un mono, después un pollo que pía como una codorniz $\mathrm{y}$, para culminar el esperpento, una rana sin cabeza. El pavor que nos provocan tamaños engendros no atañe tanto a la repulsión que nos puedan provocar estas pobres criaturitas, cuanto al pavor a la legión de monstruos que andan urgando en los laboratorios con los tornillos flojos viendo qué pueden inventar sin preguntarse para qué lo queremos. Se trata del "pensamiento único" aplicado al terreno de la biología y al que el Frankenstein de Mary Shelley queda como tierno e inocente engendro.

El camino que reivindicamos sería más bien el de la búsqueda de otra razón, de otras razones o de otros sentires ${ }^{44}$, cambio que hay que ligar no solamente a la búsqueda de una razón sino a las prácticas. Ver el modo de zafarse del pensamiento único comporta intentar no sólo pensar de otro modo, sino intentar hacer de otro modo. "Para el hombre educado en una cultura racionalista es difícil de comprender que un modo de acción preceda al modo correspondiente de conocimiento. El actuar se sigue del conocer. Mas, de hecho, cuando el conocer es radical, cuando brota de una situación radical de la condición humana, procede de un sentir, conduce a la acción. Y así, el primer modo de conocimiento puede ser una acción, un modo de conducta"4. . Hay que esbozar un marco categorial para poder pensar las alternativas y éste tendrá que pasar probablemente por el análisis de nuestras prácticas, tanto de las de los desesperanzados

39. Pensar es moverse en la razón. Zambrano M., La razón en la sombra, 82.

40. Zambrano M., La razón en la sombra, p. 82.

41. Zambrano M., La razón en la sombra, p. 85.

42. y que da título a la última obra de Hinkelammert.

43. El mapa del emperador, p. 152.

44. El sentir es preconceptual.

45. Zambrano María, El hombre y lo divino, p. 203. 
como de las de los desesperados, pues todos estamos en el mismo barco, aunque de muy diferentes modos.

Y como de cuentos chinos se trata, ahí va otro cuento de Borges referido por Foucalt al comienzo de Les mots et les choses y que podríamos titular "La lista del emperador" 4 y que muestra cómo "desde el racionalismo que algunos cultivamos, que llaman racionalismo escéptico, lo primero que se reconoce es que la dicotomía razón/pasión carece de sentido. Porque, sin ir más lejos, la razón no es sólo pasión, sino quizá la principal de las pasiones" 47 . En el Prefacio del libro mencionado, Foucault declara: "Este libro nació de un texto de Borges. De la risa que sacude al leerlo, todo lo familiar al pensamiento - al nuestro: al que tiene nuestra edad y nuestra geografía-, transtornando todas las superficies ordenadas y todos los planos que ajustan la abundancia de seres, provocando una larga vacilación e inquietud en nuestra práctica milenaria de lo Mismo y lo Otro". Este texto cita "cierta enciclopedia china" donde está escrito que "los animales se dividen en $a$ ) pertenecientes al Emperador, b) embalsamados, c) amaestrados, $d$ ) lechones, $e$ ) sirenas, $f$ ) fabulosos, $g$ ) perros sueltos, $h$ ) incluidos en esta clasificación, i) que se agitan como locos, $j$ ) innumerables, $k$ ) dibujados con un pincel finísimo de pelo de camello, $l$ ) etcétera, $m$ ) que acaban de romper el jarrón, $n$ ) que de lejos parecen moscas"4k. En el encanto exótico de otro pensamiento lo que se muestra es el límite del nuesiro, la dificultad que tenemos de pensar de otro modo. Pensar las alternativas puede ponernos en camino para intentar vencer esta dificultad.

46. Evocando también una película de Spielberg que refiere el caso histórico de un hombre, de nombre Oscar Shindler, que en la Alemania nazi se dedicaba a salvar a cuantos judíos podía bajo la pura y simple razón de "¿por qué no?"

47. Stratós Jorge, "Contra optimismo, entusiasmo", Página Abierta, No 73, 7 de junio de 1997.

48. Foucault, les Mots et les Choses Gallimard, París, 1968 (trad. siglo XXI Ed. México, 1969). La cita de Borges procede de El idioma analítico de John Wilkins, incluido en Otras Inquisiciones, Emecé, Buenos Aires, 1960, p. 142. 